\title{
25-Hydroxyvitamin $D$ levels and its relation to muscle strength, maximal oxygen consumption, and body mass index in young and middle adulthood women
}

This article was published in the following Dove Medical Press journal:

International Journal of Women's Health

\author{
Hamid Arazi \\ Ehsan Eghbali \\ Department of Exercise Physiology, \\ Faculty of Sport Sciences, \\ University of Guilan, Rasht, Islamic \\ Republic of Iran
}

Correspondence: Hamid Arazi Department of Exercise Physiology, Faculty of Sport Sciences, University of Guilan, PO Box: 4I635-I438, Rasht, Islamic Republic of Iran

Tel +989 II I 1399207

Fax +98 I33 3690675

Email hamidarazi@yahoo.com
Introduction: Vitamin D is a potent secosteroid hormone that provides many health benefits. The ubiquitous nature of vitamin D receptor (VDR) suggests widespread effect.

Purpose: The purpose of this study was to investigate the relationship between 25 -hydroxyvitamin D (25OHD) levels and muscle strength, maximal oxygen consumption ( $\left.\mathrm{VO}_{2} \mathrm{max}\right)$, and body mass index (BMI) in Iranian young and middle adulthood women.

Participants and methods: A cross-sectional descriptive study was conducted in 182 healthy Iranian women within the age range of 26-60 years. Body weight and height were measured, and BMI was calculated. $\mathrm{VO}_{2} \max$ was determined by the Rockport test. Muscle strength was determined by the chest press, leg press, and hand grip test. Also, circulating levels of 25OHD were evaluated.

Results: Results showed a significant relationship between $25 \mathrm{OHD}$ levels and $\mathrm{BMI}, \mathrm{VO}_{2} \max$, and muscle strength (chest press, leg press, hand grip dominant hand [HGDH], and hand grip nondominant hand [HGNDH]) in young and middle adulthood women (BMI in young and middle adulthood: $\mathrm{r}=-0.48, P<0.001$ and $\mathrm{r}=-0.27, P=0.01$, respectively; $\mathrm{VO}_{2}$ max in young and middle adulthood women: $\mathrm{r}=0.69, P<0.001$ and $\mathrm{r}=0.57, P<0.001$, respectively; chest press, leg press, HGDH, and HGNDH in young adulthood: $\mathrm{r}=0.58, \mathrm{r}=0.59, \mathrm{r}=0.65$, and $\mathrm{r}=0.42$, respectively, $P<0.001$; and in middle adulthood: $\mathrm{r}=0.73, \mathrm{r}=0.34, \mathrm{r}=0.66$, and $\mathrm{r}=0.55$, respectively, $P \leq 0.001$ ). Multiple linear regression analysis showed that higher levels of $\mathrm{VO}_{2} \mathrm{max}, \mathrm{HGDH}$, and chest press predicted higher 25OHD levels in the young adulthood women $\left(\mathrm{R}^{2}=0.75 ; \beta=0.39, \beta=0.35\right.$, and $\beta=0.30$, respectively; $P<0.001$ ). Moreover, $\mathrm{VO}_{2} \max$ and $\mathrm{HGDH}$ were the strongest predictor of $25 \mathrm{OHD}$ levels in the middle adulthood women $\left(\mathrm{R}^{2}=0.71 ; \beta=0.35, \beta=0.40\right.$, respectively; $\left.P<0.001\right)$.

Conclusion : Based on the results, it could be concluded that $\mathrm{VO}_{2} \max$ and strength are useful indirect marker for 25OHD levels in the young and middle adulthood women. It also seems that $\mathrm{VO}_{2}$ max and $\mathrm{HGDH}$ strength had stronger associations with 25OHD levels in the young adulthood women, and chest press and HGDH had stronger associations with 25OHD levels in the middle adulthood women.

Keywords: vitamin D, 25OHD, hand grip strength, aerobic power, $\mathrm{VO}_{2}$ max, $\mathrm{BMI}$

\section{Introduction}

Vitamin D is an essential nutrient obtained through diet and sunlight exposure. ${ }^{1}$ It plays an important role in calcium and phosphorus balance and bone health. Moreover, it has a role in many pleiotropic functions, such as regulating kidney function, heart, immune system, skeletal muscle, anti-inflammatory, anti-apoptotic, antifibrotic, cell differentiation, and proliferation functions. ${ }^{2,3}$ 
Recent studies suggest that vitamin D preserves physical activity in athletes and other active individuals. For example, the maximum amount of oxygen may be related to the status of vitamin D. Poor vitamin D status has an effect on muscle strength and may play a role in protein synthesis through its receptors in muscle tissue. ${ }^{1}$ Low levels of vitamin D are associated with chronic nonskeletal and autoimmune diseases, including cardiovascular disease, high blood pressure, diabetes mellitus, depression, multiple sclerosis, and rheumatoid arthritis. ${ }^{4,5}$ It is also believed that vitamin D acts as a potent antioxidant against free radical damage and may stimulate cell differentiation; hence, it has a potent anticancer activity ${ }^{6,7}$ Vitamin D is known for its calciotropic effects and is involved in regulating calcium in the blood and bones. ${ }^{6}$ Studies have shown that vitamin D supplementation, with and without calcium, can improve the muscle strength of people with vitamin D deficiency (below $25 \mathrm{nmol} / \mathrm{L}$ ); however, there are a few compelling results with low statistical populations. ${ }^{8}$ Vitamin D is often linked to the level of physical activity and being overweight or obese, ${ }^{9}$ and it is likely that the relationship between vitamin $\mathrm{D}$ status and muscle strength is related to one or both of these factors. ${ }^{10}$

The importance of vitamin D in skeletal muscle function mediated by the vitamin D receptors (VDR) has been shown in both nuclei and membranes of the human skeletal muscle fiber cells. ${ }^{11}$ VDR is found in the kidneys, lungs, intestines, gonads, skin, smooth muscle, heart muscle, and skeletal muscle. ${ }^{1}$ These processes are mediated through genomic and non-genomic mechanisms. ${ }^{12}$ Both genomic and non-genomic mechanisms are involved in regulating metabolic processes, transcription, and gene expression in skeletal muscles by stimulating intracellular calcium control (calcium channel membrance regulation), myocytic differentiation, contraction of protein expression, hypertrophy, and improved mitochondrial function. It has been suggested that vitamin D can improve contraction, growth, and muscle strength. ${ }^{13}$ Vitamin D may also be involved in muscle tissue regeneration. ${ }^{13}$ Recent studies have shown that 25-hydroxyvitamin D (25OHD) deficiency reduces signaling pathways for growth and survival such as MAPK and AKT, and weakens development of muscle cells. ${ }^{13}$ The skeletal muscle is a 25OHD storage site, which was found to express megalin and cubilin, proteins necessary for the endocytic internalization of DBP-bound 25OHD, and muscle fibers were noted to retain substantially higher proportions of tritium-labeled 25OHD than bone cells. ${ }^{14}$

Vitamin D deficiency is associated with an increase in cardiovascular incompatibility and mortality, possibly due to cardiovascular risk factors such as high blood pressure and type 2 diabetes mellitus. ${ }^{1}$ Low cardiorespiratory fitness is an independent risk factor for cardiovascular patients and their mortality. It has recently been shown that maximal oxygen consumption ( $\left.\mathrm{VO}_{2} \max \right)$ is directly related to levels of serum vitamin D in humans. ${ }^{1}$ Quantitative studies have been done on association between cardiorespiratory fitness and serum 25OHD concentration. Mowry et al showed that there was a positive correlation between serum $\mathrm{VO}_{2} \max$ and 25OHD levels in healthy women aged 16-24 years. ${ }^{15}$

Studies showed that vitamin D deficiency is one of the common causes of obesity. ${ }^{16}$ Therefore, the serum level of vitamin $\mathrm{D}$, which is the major form of vitamin $\mathrm{D}$ in circulation, used to measure the status of human vitamin D, has an inverse relationship not only with total fat but also with visceral fat and subcutaneous fat. ${ }^{17}$ Lower levels of vitamin $\mathrm{D}$ in obese individuals are associated with a suppressive increase in serum parathyroid hormone, which, in turn, may increase weight through effects on lipogenesis due to increased penetration of calcium into adipocytes. ${ }^{18}$ If this hypothesis is correct, the 25OHD serum levels increase in the summer months are expected to reduce body weight. In other words, it has been suggested that the reduction in the 25OHD serum level is a result of obesity, not the cause of it, and fat tissue also seems to store a significant amount of vitamin D. ${ }^{18}$

Studies have shown conflicting findings about the relationship between vitamin $\mathrm{D}$ and muscle strength, muscle mass, and body fat. The result of Grimaldi et al suggested that vitamin $\mathrm{D}$ has different effects on upper and lower body strength. ${ }^{19}$ Moreover, Ceglia et al concluded that no relationship was found between $250 \mathrm{HD}$ levels and fat free mass and hand grip strength. ${ }^{20}$ Furthermore, there is evidence that increasing the concentration of 25OHD stimulates lipogenesis and inhibits lipolysis, thereby increasing triglyceride reserves in obese individuals. ${ }^{21,22}$ Although more research has been done in the young population, in the other age groups not much research has been done. Due to possible mechanisms proposed, it is hypothesized that vitamin $\mathrm{D}$ is associated with muscle strength, body mass index (BMI), and $\mathrm{VO}_{2}$ max in young and middle adulthood women. Furthermore, the relationship between vitamin D and $\mathrm{VO}_{2}$ max, muscle strength, and BMI in Iranian women has not been studied yet, and this association may not be the same as in other populations. Therefore, in this study, researchers were seeking to investigate the relationship between these variables and vitamin D levels in Iranian young and middle adulthood women. 


\section{Participants and methods}

It was a cross-sectional descriptive study on 182 healthy Iranian women with age range of 26-60 years. Participants were divided into two groups according to their age: young adulthood (25-45 years) and middle adulthood (46-60 years). ${ }^{23,24}$ Participants included were people who had normal activity (activities related to daily living that may include house cleaning, grocery shopping, laundry, etc, but not specifically games/sports and other forms of physical activity) for more than 20 months, without a history of use of oral contraceptives and hormones, smoking, gravidity and parity, hypertension, cardiovascular disease, and exercise habits. The participants were instructed to refrain from consuming any caffeine-containing drinks for 24 hours prior to the study, and were also asked to avoid strenuous physical activity or intense exercise for 24 hours before participating in the study. Setting the days of each test was based on the history of menstruation. The study was approved by the University Ethics Committee of Guilan, Iran, and conducted according to the Declaration of Helsinki.

Participants filled in consent forms, general health information and were asked questions about their diet. In addition, circulating level of 25OHD was measured. After explaining the procedures and working methods, measurements were carried out. First, the anthropometric indices and then physiological parameters were measured. All measurements were performed between 8:00 and 12:00 AM. Participants in the study had usual diets (their diet did not contain food supplements, and also consumed less food containing vitamin $\mathrm{D}$ in their daily diet) and received little sunlight due to their geographical, religious conditions, and the type of cover they had.

Height was measured using a stadiometer to the nearest $0.01 \mathrm{~cm}$. Body weight was measured using a standard balance beam scale to the nearest 0.1 kilogram $(\mathrm{kg})$. BMI was calculated as body weight divided by the square of height $\left(\mathrm{kg} / \mathrm{m}^{2}\right)$.

\section{Upper and lower body muscle strength}

To measure the strength, one-repetition maximum (1RM) in the chest press and leg press exercises were used. In 1RM in the chest press and leg press, the maximum amount of weight that the subject can move once was calculated using the formula: ${ }^{25}$

$$
\begin{aligned}
1 \mathrm{RM}= & \mathrm{Load} /(1.0278-0.0278[\mathrm{number} \text { of } \\
& \text { repetitions to exhaustions] })
\end{aligned}
$$

\section{Hand grip strength}

Hand grip strength was measured using a digital dynamometer (Saehan, model SH5003; Saehan Corporation, Masan, South Korea). The participants performed the test in a sitting position on a chair, with their elbow extended to $180^{\circ}$ along the vertical axis with a neutral wrist position. This test was repeated thrice with 15 seconds between trials with both dominant and nondominant hands, and the mean value was recorded in kilogram (the reliability $\mathrm{r}=0.96$ for the present device was recognized as high). ${ }^{26}$

\section{Aerobic power}

To measure the participants' aerobic power, the researchers used the Rockport test. The participants were asked to walk fast for 1,608 $\mathrm{m}$. Then, the time and heart rate were jotted down at the end of the walking and the aerobic power was measured using the following formula: ${ }^{27,28}$

$$
\begin{aligned}
\mathrm{VO}_{2} \max (\mathrm{mL} / \mathrm{kg} / \mathrm{min})= & 132.853+(6.315 \times \text { gender })- \\
& (0.0769 \times \text { weight })-(0.3877 \times \text { age }) \\
& -(3.2649 \times \text { time })-(0.1565 \times \\
& \text { heart rate })
\end{aligned}
$$

Gender $=1$ for males and 0 for females, weight is in pounds, time is in minutes, heart rate is beats per minute.

\section{Blood measurements}

Fasting blood samples were taken from a forearm vein between 8:00 and 10:00 AM (measurement was taken in the spring). The $25 \mathrm{OHD}$ level was determined by enzyme-linked immunosorbent assay method with sensitivity of $<4.0 \mathrm{ng} / \mathrm{mL}$ (Stat Fax 2100; Awareness Technology Inc., Palm City, FL, USA). Inter- and intra-assay coefficients of variation were $8.2 \%$ and $11.3 \%$, respectively. Participants were divided into the $25 \mathrm{OHD}$ sufficient or normal group ( $\geq 30 \mathrm{ng} / \mathrm{mL}$ ), and the insufficient group ( $\leq 29 \mathrm{ng} / \mathrm{mL}){ }^{29,30}$

\section{Statistical analyses}

By using the data related to the variables, the mean and SD of participants' scores were calculated. The data distributions were found abnormal by Kolmogorov-Smirnov test, and the nonparametric test of Spearman correlation coefficient was used to determine the association between the mentioned variables. Based on the correlated variables, nonparametric multiple linear regression models were then fitted. Statistical operation of the present study was performed using SPSS 20 software (IBM Corporation, 
Armonk, NY, USA) and Excel 2010 (Microsoft Corporation, Redmond, WA, USA). The significance level was considered as $P \leq 0.05$ at all stages.

\section{Result}

The mean serum $250 H D$ concentration in the study population was $38.48 \pm 16.93 \mathrm{ng} / \mathrm{mL}(43.71 \pm 18.42 \mathrm{ng} / \mathrm{mL}$ in young adulthood women and $32.51 \pm 12.73 \mathrm{ng} / \mathrm{mL}$ in middle adulthood women). In young adulthood women, $59.79 \%$ participants had vitamin D sufficiency, and $40.20 \%$ had vitamin D insufficiency. In middle adulthood women, $48.23 \%$ participants had vitamin D sufficiency, and $51.76 \%$ had vitamin D insufficiency (Figure 1).

Table 1 shows the descriptive characteristics of 182 women included in the study (mean age of young adulthood women $=32.08 \pm 4.94$ years and mean age of middle adulthood women $=53.94 \pm 3.32$ years $)$. The values of Spearman correlation coefficient between $25 \mathrm{OHD}$ levels, $\mathrm{BMI}, \mathrm{VO}_{2} \max$, and muscle strength in our subjects are shown in Table 2. According to our results, 25OHD concentrations were significant and inversely associated with BMI in young and middle adulthood women ( $\mathrm{r}=-0.48, P<0.001$ and $\mathrm{r}=-0.27$, $P=0.01$, respectively). Also, there was a statistically significant correlation between $25 \mathrm{OHD}$ levels and $\mathrm{VO}_{2} \max$ in young and middle adulthood women $(\mathrm{r}=0.69, P<0.001$ and $\mathrm{r}=0.57, P<0.001$, respectively). Additionally, positive correlations were found between $250 \mathrm{HD}$ levels and chest press, leg press, hand grip dominant hand (HGDH), and hand grip nondominant hand (HGNDH) in young and middle adulthood women (in young adulthood women: $\mathrm{r}=0.58, \mathrm{r}=0.59, \mathrm{r}=0.65$,

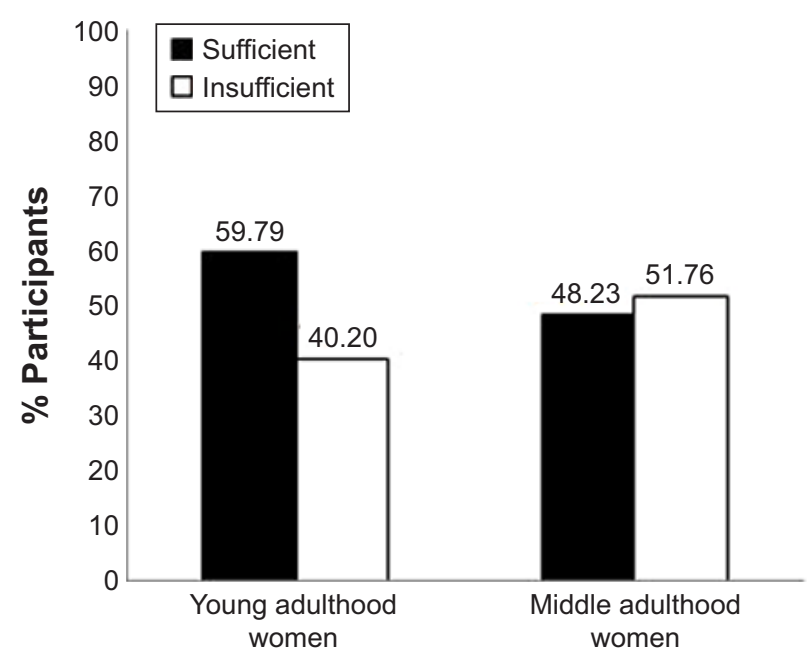

Figure I 25OHD status in young adulthood $(n=97)$ and middle adulthood women $(\mathrm{n}=85)$.

Note: Subjects were divided into a $250 \mathrm{HD}$ sufficient or normal group ( $\geq 30 \mathrm{ng} / \mathrm{mL}$ ) and an insufficient group ( $\leq 29 \mathrm{ng} / \mathrm{mL}$ ).

Abbreviation: 25OHD, 25-hydroxyvitamin D. and $\mathrm{r}=0.42$, respectively; $P<0.001$ and in middle adulthood women: $\mathrm{r}=0.73, \mathrm{r}=0.34, \mathrm{r}=0.66$, and $\mathrm{r}=0.55$, respectively; $P \leq 0.001)$ (Table 2).

The results of stepwise multiple linear regression analysis models are shown in Table 3 . $\mathrm{VO}_{2} \max , \mathrm{HGDH}$, and chest press were the strongest predictor of $250 \mathrm{HD}$ levels in young adulthood women $\left(\mathrm{R}^{2}=0.75 ; \beta=0.39, \beta=0.35\right.$, and $\beta=0.30$, respectively; $P<0.001$ ), also, $\mathrm{VO}_{2} \max$ and $\mathrm{HGDH}$ were the strongest predictor of $25 \mathrm{OHD}$ levels in middle adulthood women $\left(\mathrm{R}^{2}=0.71 ; \beta=0.35\right.$ and $\beta=0.40$, respectively; $\left.P<0.001\right)$ (Table 3$)$.

\section{Discussion}

The aim of the present study was to investigate the relationship between vitamin $\mathrm{D}$ levels and $\mathrm{VO}_{2}$ max, muscle strength, and BMI in young and middle adulthood women. The results indicated that vitamin $\mathrm{D}$ has a relatively good relationship with $\mathrm{VO}_{2}$ max and muscle strength in young and middle adulthood women. The main findings of this study indicated that $\mathrm{VO}_{2}$ max and $\mathrm{HGDH}$ strength are the strongest predictors of $25 \mathrm{OHD}$ levels in young and middle adulthood women.

The types of molecular pathways by which vitamin D can affect muscle cells have been somewhat discovered. These effects may occur quickly; it has been suggested that vitamin D will interact with calcium in muscle function namely contraction, plasticity, mitochondrial function, insulin signaling, and fuel handling. ${ }^{31}$ While there was recent evidence for the link between vitamin D and mitochondrial function, potential changes in muscle substrate metabolism may help explain insulin resistance, intramuscular fatty deposition, and muscle weakness in people with vitamin D deficiency. 25OHD serum levels are related to the recovery rate of postexercise muscular creatine phosphate reserves, and it is suggested that there is wider association with the production of ATP and oxidative function. ${ }^{14}$ Vitamin D can lead to delayed effects on muscle via gene expression. This involves binding of the 1,25OHD-VDR-RXR (retinoid X-receptor) complex to vitamin D response elements of DNA and includes effects in the expression of contractile proteins and myogenic transcription factors that affect muscle development. ${ }^{32}$

The results of this study indicated that there was a significant relationship between 25OHD levels and upper and lower body muscle strength and hand grip strength in young and middle adulthood women. In this regard, the findings of Von Hurst et al suggested that there was a significant correlation between $250 H D$ concentration and hand grip strength in the young population. ${ }^{10}$ The results of Granic et al indicated that low levels of 25OHD were associated with an increase in the speed of muscle strength reduction in men (age $\geq 85$ years). ${ }^{33}$ 
Table I Characteristics of study population

\begin{tabular}{|c|c|c|c|}
\hline \multirow[t]{2}{*}{ Variables } & \multicolumn{3}{|l|}{ Mean \pm SD } \\
\hline & Young adulthood women (97) & Middle adulthood women (85) & Overall (1 82) \\
\hline Age (years) & $32.08 \pm 4.94$ & $53.94 \pm 3.32$ & $42.29 \pm 11.73$ \\
\hline Height (cm) & $157.93 \pm 5.84$ & $158.39 \pm 5.05$ & $158.15 \pm 5.47$ \\
\hline Weight (kg) & $61.19 \pm 5.24$ & $75.59 \pm 8.18$ & $67.92 \pm 9.87$ \\
\hline BMI $\left(\mathrm{kg} / \mathrm{m}^{2}\right)$ & $24.93 \pm 4.33$ & $29.17 \pm 3.78$ & $26.91 \pm 4.59$ \\
\hline $25 \mathrm{OHD}(\mathrm{ng} / \mathrm{mL})$ & $43.71 \pm 18.42$ & $32.5 I \pm 12.73$ & $38.48 \pm 16.93$ \\
\hline $\mathrm{VO}_{2} \max (\mathrm{mL} / \mathrm{kg} / \mathrm{min})$ & $34.95 \pm 7.00$ & $24.23 \pm 3.82$ & $29.94 \pm 7.84$ \\
\hline Chest press (kg) & $31.16 \pm 3.61$ & $23.46 \pm 4.32$ & $27.56 \pm 5.5 \mathrm{I}$ \\
\hline Leg press (kg) & $68.56 \pm 12.10$ & $44.74 \pm 8.40$ & $57.43 \pm 15.89$ \\
\hline HGDH (kg) & $30.52 \pm 3.04$ & $24.02 \pm 3.54$ & $27.49 \pm 4.61$ \\
\hline HGNDH (kg) & $25.50 \pm 3.11$ & $21.04 \pm 3.65$ & $23.42 \pm 4.03$ \\
\hline
\end{tabular}

Abbreviations: 25OHD, 25-hydroxyvitamin D; BMI, body mass index; $\mathrm{HGDH}$, hand grip dominant hand; $\mathrm{HGNDH}$, hand grip nondominant hand; VO ${ }_{2}$ ax, maximal oxygen consumption.

In addition, Grimaldi et al suggested that vitamin D has different effects on upper and lower body strength. They stated that the mechanism of this difference was not known, but it could be due to differences in androgenic effects or differences in expression of VDR. ${ }^{19}$

Contrary to these results, studies on young and older women with baseline levels of $25 \mathrm{OHD}$ of $50 \mathrm{nmol} / \mathrm{L}^{34}$ and postmenopausal women (age $\sim 60$ years) with $25 \mathrm{OHD}$ of $50 \mathrm{nmol} / \mathrm{L}$, showed no relationship between vitamin $\mathrm{D}$ status and functional tests of muscle strength. ${ }^{35}$ Glerup et al suggested that moderate levels of vitamin D deficiency in sarcopenia or muscle weakness may not be significantly associated with young people in the general population. ${ }^{36}$ Ceglia et al also concluded that there was no relationship between $25 \mathrm{OHD}$ and fat free mass and hand grip strength. ${ }^{20}$

As mentioned, the importance of vitamin $\mathrm{D}$ in the functioning of skeletal muscle is due to the presence of VDR in muscle tissue; vitamin D causes normal muscle function. The effect of VDR is applied through genomic and non-genomic pathways. The VDR develops phospholipid metabolism in the muscles; in addition, it has been reported that the non-genomic mechanism involves one or more pathways including circular c-AMP/PKA, PKC, calmodulin kinase, PKB/AKT, and MAPK that increase the leucine stimulating effects and promotion of promygenic and angiogenic growth factors. These phenomena lead to the stimulation of protein synthesis in the muscles, increase the number of type II myositis, and in addition, may contribute to the improvement of contraction, growth, and post-traumatic muscle reconstruction. ${ }^{13}$ In this regard, some studies have shown that low levels of 25OHD can disrupt the development of muscle cells and reduce signaling pathways that are essential for muscle growth and survival. Briefly, there is new information on myoblast migratory signals, that is, the important role of PI3K/AKT and MAPK/ERK pathways in migrating myoblast has been clarified. As mentioned, these paths are mediated by vitamin D. ${ }^{37,38}$ It has recently been discovered that $25 \mathrm{OHD}$ has a transcription-enhancing role in proteins that are not involved in calcium metabolism. One of these proteins is

Table 2 Associations between BMI, $\mathrm{VO}_{2}$ max, chest press, leg press, $\mathrm{HGDH}$, and $\mathrm{HGNDH}$ and 25OHD

\begin{tabular}{|l|l|l|l|l|l|l|}
\hline \multirow{2}{*}{ Variables } & Young adulthood women (97) & \multicolumn{4}{l|}{ Middle adulthood women (85) } & \multicolumn{4}{l|}{ Overall (182) } \\
\cline { 2 - 7 } & $\boldsymbol{r}$ & $\boldsymbol{P}$ & $\boldsymbol{r}$ & $\boldsymbol{P}$ & $\boldsymbol{r}$ & \multicolumn{1}{l|}{} \\
\hline $\mathrm{BMI}\left(\mathrm{kg} / \mathrm{m}^{2}\right)$ & -0.48 & $<0.00 \mathrm{I}^{\mathrm{a}}$ & -0.27 & $0.0 \mathrm{I}^{\mathrm{a}}$ & -0.50 & $<0.00 \mathrm{I}^{\mathrm{a}}$ \\
\hline $\mathrm{VO}_{2} \mathrm{max}(\mathrm{mL} / \mathrm{kg} / \mathrm{min})$ & 0.69 & $<0.00 \mathrm{I}^{\mathrm{a}}$ & 0.57 & $<0.00 \mathrm{I}^{\mathrm{a}}$ & 0.64 & $<0.00 \mathrm{I}^{\mathrm{a}}$ \\
\hline Chest press $(\mathrm{kg})$ & 0.58 & $<0.00 \mathrm{I}^{\mathrm{a}}$ & 0.73 & $<0.00 \mathrm{I}^{\mathrm{a}}$ & 0.64 & $<0.00 \mathrm{I}^{\mathrm{a}}$ \\
\hline Leg press $(\mathrm{kg})$ & 0.59 & $<0.00 \mathrm{I}^{\mathrm{a}}$ & 0.34 & $0.00 \mathrm{I}^{\mathrm{a}}$ & 0.56 & $<0.00 \mathrm{I}^{\mathrm{a}}$ \\
\hline $\mathrm{HGDH}(\mathrm{kg})$ & 0.65 & $<0.00 \mathrm{I}^{\mathrm{a}}$ & 0.66 & $<0.00 \mathrm{I}^{\mathrm{a}}$ & 0.65 & $<0.00 \mathrm{I}^{\mathrm{a}}$ \\
\hline HGNDH $(\mathrm{kg})$ & 0.42 & $<0.00 \mathrm{I}^{\mathrm{a}}$ & 0.55 & $<0.00 \mathrm{I}^{\mathrm{a}}$ & 0.54 & $<0.00 \mathrm{I}^{\mathrm{a}}$ \\
\hline
\end{tabular}

Note: aSignificance at the $\leq 0.05$ level.

Abbreviations: 25OHD, 25-hydroxyvitamin D; BMI, body mass index; $\mathrm{HGDH}$, hand grip dominant hand; $\mathrm{HGNDH}$, hand grip nondominant hand; $\mathrm{VO}_{2}$ max, maximal oxygen consumption. 
Table 3 Multiple linear regression analysis with levels of $25 \mathrm{OHD}$ as the dependent variable

\begin{tabular}{|c|c|c|c|c|c|c|c|c|c|c|c|c|}
\hline \multirow[t]{2}{*}{ Variable } & \multicolumn{4}{|c|}{ Young adulthood women (97) } & \multicolumn{4}{|c|}{ Middle adulthood women (85) } & \multicolumn{4}{|c|}{ Overall (182) } \\
\hline & B & $\beta$ & $P$ & $R^{2}$ & B & $\beta$ & $P$ & $R^{2}$ & B & $\beta$ & $P$ & $R^{2}$ \\
\hline BMI $\left(\mathrm{kg} / \mathrm{m}^{2}\right)$ & -0.457 & -0.170 & 0.004 & 0.751 & - & - & - & 0.719 & -0.396 & -0.163 & 0.011 & 0.540 \\
\hline $\mathrm{VO}_{2} \max (\mathrm{mL} / \mathrm{kg} / \mathrm{min})$ & 0.843 & 0.394 & $<0.00$ I & & 0.803 & 0.352 & $<0.001$ & & 0.531 & 0.318 & $<0.001$ & \\
\hline Chest press (kg) & 1.245 & 0.304 & $<0.00$ I & & 0.577 & 0.318 & $<0.001$ & & 0.362 & 0.177 & 0.027 & \\
\hline Leg press (kg) & - & - & - & & - & - & - & & - & - & - & \\
\hline $\mathrm{HGDH}(\mathrm{kg})$ & 1.673 & 0.355 & $<0.00$ I & & 0.943 & 0.405 & $<0.001$ & & 0.533 & 0.214 & 0.007 & \\
\hline HGNDH (kg) & - & - & - & & - & - & - & & - & - & - & \\
\hline
\end{tabular}

Abbreviations: 25OHD, 25-hydroxyvitamin D; B, unstandardized regression coefficient; BMI, body mass index; $\beta$, standardized regression coefficient; HGDH, hand grip dominant hand; $\mathrm{HGNDH}$, hand grip nondominant hand; $\mathrm{VO}_{2} \max$, maximal oxygen consumption.

related to skeletal muscle, IGFBP- $3 .{ }^{39}$ This protein is part of the family of proteins bound to IGF. ${ }^{40}$

The results of this study indicated that there was a significant relationship between $25 \mathrm{OHD}$ and $\mathrm{VO}_{2}$ max levels in young and middle adulthood women. In this regard, Ardestani et al showed that serum vitamin D levels has a positive correlation with $\mathrm{VO}_{2}$ max, and $\mathrm{VO}_{2}$ max levels predict $25 \mathrm{OHD}$ levels in youngsters. They also argued that this ratio is higher in people with lower physical activity levels. It has been suggested that 25OHD contributes to cardiorespiratory fitness. ${ }^{41}$ Furthermore, Mowry et al showed a positive relationship between $\mathrm{VO}_{2}$ max and serum $25 \mathrm{OHD}$ levels in young women. ${ }^{15}$

$\mathrm{VO}_{2}$ max is set by cardiac output, arterial oxygen content, shunting of blood to active muscle, and extraction of oxygen by muscles. ${ }^{41}$ A low level of $25 \mathrm{OHD}$ may be associated with myocardial hypertrophy, hypertension, and endothelial dysfunction. ${ }^{42}$ As a result, low levels of 25OHD may reduce cardiac output and increase the peripheral vascular resistance, thereby reducing $\mathrm{VO}_{2}$ max. ${ }^{1}$ Reducing serum levels of $25 \mathrm{OHD}$ can increase myocardial hypertrophy, hypertension, and endothelial dysfunction through VDR; consequently, decreasing vitamin $\mathrm{D}$ levels may reduce cardiac output and increase the peripheral arteries resistance thereby reducing $\mathrm{VO}_{2}$ max. ${ }^{41}$ In addition, vitamin $\mathrm{D}$ deficiency can cause muscle atrophy and change the type of muscle fibers IIa to IIb. ${ }^{41}$ Moreover, other cardiovascular risk factors such as insulin resistance, hypertension, and arterial stiffness can increase the negative effect of vitamin $\mathrm{D}$ on $\mathrm{VO}_{2}$ max among inactive people. ${ }^{43}$

The results showed that there was a significant negative relationship between the 25OHD levels and BMI in young and middle adulthood women. The epidemiological association between obesity and vitamin $\mathrm{D}$ is complex and potentially bidirectional. Studies have shown that high BMI leads to a decrease in $25 \mathrm{OHD} ;{ }^{21}$ on the other hand, the $25 \mathrm{OHD}$ contribution to BMI is negligible. Similarly, clinical trials that were used in weight-loss interventions reported an increase in serum concentrations of $25 \mathrm{OHD}$ after intervention. ${ }^{44}$ Vitamin D is fat soluble and, therefore, stored easily in the adipose tissue. With excess body fat being expected to store higher concentrations of serum 25OHD. Previous studies have shown an increase in vitamin $\mathrm{D}$ uptake by adipose tissue and $>50 \%$ decreased bioavailability of cutaneous vitamin $\mathrm{D}$ in obese subjects. ${ }^{21}$ In contrast, there is evidence that increasing the concentration of 25OHD stimulates lipogenesis and inhibits lipolysis, thereby increasing triglyceride reserves in obese individuals. ${ }^{21,22}$

The results of Rontoyanni et al suggested that obese and overweight Mexican adults are facing the risk of decreased 25OHD serum levels when compared to normal-weight groups. ${ }^{21}$ The fat mass has a reversible relationship with the vitamin $\mathrm{D}$, and those with higher fat mass may be at the highest risk for insufficient and deficient vitamin D status. ${ }^{45}$

If there is a causal relationship, regardless of the cause, changes in weight and serum 25OHD levels are expected in individuals after some time. However, Young et al showed that there was no significant correlation between changes in fat and serum 25OHD, although there was a significant and inverse relationship at baseline levels. ${ }^{17}$ In addition, the relationship between BMI and 25OHD appears to be due to the fact that obesity reduces serum levels of $25 \mathrm{OHD}$ and is probably due to increased vitamin D storage in adipose tissue. ${ }^{46}$ The results of Jorde et al showed that there was a strong correlation between BMI and serum 25OHD levels in individuals. Very obese individuals need a high dose of vitamin D compared to lean subjects to get the same level of 25OHD. ${ }^{18}$

There are limitations to our study, including its crosssectional design and the number of participants in our study, which was not very high. Also, we did not record the exact detail of daily diet. Future studies are required to examine the issue in larger sample size, larger age groups, and among men and women for comparison. 


\section{Conclusion}

Based on the results, it can be concluded that there was a significant relationship between vitamin $\mathrm{D}$ and $\mathrm{VO}_{2} \max$, muscle strength, and BMI in women; nevertheless, $\mathrm{VO}_{2} \max$ and HGDH strength had a stronger association with $25 \mathrm{OHD}$ levels in young adulthood women, and chest press and $\mathrm{HGDH}$ had a stronger association with 25OHD levels in middle adulthood women. Furthermore, $\mathrm{VO}_{2} \mathrm{max}$ and $\mathrm{HGDH}$ strength are stronger predictors of $25 \mathrm{OHD}$ levels in women. To conclude, this requires more extensive studies with larger samples.

\section{Acknowledgment}

The authors hereby declare their gratitude to all those who participated as subjects in this study.

\section{Author contributions}

HA designed the research. EE conducted the research including sample analysis. HA and EE analyzed the data and wrote the paper. Both authors contributed toward data analysis, drafting and revising the paper, gave final approval of the version to be published and agree to be accountable for all aspects of the work.

\section{Disclosure}

The authors report no conflicts of interest in this work.

\section{References}

1. Moran DS, McClung JP, Kohen T, Lieberman HR. Vitamin D and physical performance. Sports Med. 2013;43(7):601-611.

2. Dahlquist DT, Dieter BP, Koehle MS. Plausible ergogenic effects of vitamin D on athletic performance and recovery. J Int Soc Sports Nutr. 2015;12(1):1-12.

3. Neal S, Sykes J, Rigby M, Hess B. A review and clinical summary of vitamin D in regard to bone health and athletic performance. Phys Sportsmed. 2015;43(2):161-168.

4. Halliday TM, Peterson NJ, Thomas JJ, Kleppinger K, Hollis BW, Larson-Meyer DE. Vitamin D status relative to diet, lifestyle, injury, and illness in college athletes. Med Sci Sports Exerc. 2011;43(2):335-343.

5. Holick MF. Vitamin D deficiency. NEngl J Med. 2007;357(3):266-281.

6. Bartoszewska M, Kamboj M, Patel DR, Vitamin D. Vitamin D, muscle function, and exercise performance. Pediatr Clin North Am. 2010; 57(3):849-861.

7. Verstuyf A, Carmeliet G, Bouillon R, Mathieu C. Vitamin D: a pleiotropic hormone. Kidney Int. 2010;78(2):140-145.

8. Stockton KA, Mengersen K, Paratz JD, Kandiah D, Bennell KL. Effect of vitamin D supplementation on muscle strength: a systematic review and meta-analysis. Osteoporos Int. 2011;22(3):859-871.

9. Shoben AB, Kestenbaum B, Levin G, et al. Seasonal variation in 25-hydroxyvitamin D concentrations in the cardiovascular health study. Am J Epidemiol. 2011;174(12):1363-1372.

10. Von Hurst PR, Conlon C, Foskett A. Vitamin D status predicts handgrip strength in young adult women living in Auckland, New Zealand. J Steroid Biochem Mol Biol. 2013;136:330-332.

11. Barker T, Schneider ED, Dixon BM, Henriksen VT, Weaver LK. Supplemental vitamin D enhances the recovery in peak isometric force shortly after intense exercise. Nutr Metab. 2013;10(1):69.
12. Dirks-Naylor AJ, Lennon-Edwards S. The effects of vitamin D on skeletal muscle function and cellular signaling. $J$ Steroid Biochem Mol Biol. 2011;125(3-5):159-168.

13. Owens DJ, Fraser WD, Close GL. Vitamin D and the athlete: emerging insights. Eur J Sport Sci. 2015;15(1):73-84.

14. Girgis CM, Clifton-Bligh RJ, Turner N, Lau SL, Gunton JE. Effects of vitamin D in skeletal muscle: falls, strength, athletic performance and insulin sensitivity. Clin Endocrinol. 2014;80(2):169-181.

15. Mowry DA, Costello MM, Heelan KA. Association among cardiorespiratory fitness, body fat, and bone marker measurements in healthy young females. $J$ Am Osteopath Assoc. 2009;109(10):534-539.

16. Foss YJ. Vitamin D deficiency is the cause of common obesity. Med Hypotheses. 2009;72(3):314-321.

17. Young KA, Engelman CD, Langefeld CD, et al. Association of plasma vitamin D levels with adiposity in Hispanic and African Americans. J Clin Endocrinol Metab. 2009;94(9):3306-3313.

18. Jorde R, Sneve M, Emaus N, Figenschau Y, Grimnes G. Cross-sectional and longitudinal relation between serum 25-hydroxyvitamin $\mathrm{D}$ and body mass index: the Tromsø study. Eur J Nutr. 2010;49(7):401-407.

19. Grimaldi AS, Parker BA, Capizzi JA, et al. $25(\mathrm{OH})$ vitamin D is associated with greater muscle strength in healthy men and women. Med Sci Sports Exerc. 2013;45(1):157-162.

20. Ceglia L, Chiu GR, Harris SS, Araujo AB. Serum 25-hydroxyvitamin D concentration and physical function in adult men. Clin Endocrinol. 2011;74(3):370-376.

21. Rontoyanni V, Avila J, Kaul S, Wong R, Veeranki S. Association between Obesity and Serum 25(OH)D Concentrations in Older Mexican Adults. Nutrients. 2017;9(2):97.

22. Zemel MB. Regulation of adiposity and obesity risk by dietary calcium: mechanisms and implications. J Am Coll Nutr. 2002;21(2): 146S-151S.

23. Hadjigeorgiou C, Solea A, Querol SE, et al. Disordered eating in three different age groups in Cyprus: a comparative cross-sectional study. Public Health. 2018;162:104-110.

24. Koch V, Pokorn D. Comparison of nutritional habits among various adult age groups in Slovenia. Nutrition Research. 1999;19(8):1153-1164.

25. Brzycki M. Strength testing - predicting a one-rep max from reps-tofatigue. J Phys Educ Recreat Dance. 1993;64(1):88-90.

26. Li K, Hewson DJ, Duchêne J, Hogrel JY. Predicting maximal grip strength using hand circumference. Man Ther. 2010;15(6): 579-585.

27. Kline GM, Porcari JP, Hintermeister R, et al. Estimation of VO2max from a one-mile track walk, gender, age, and body weight. Med Sci Sports Exerc. 1987;19(3):253-259.

28. Dolgener FA, Hensley LD, Marsh JJ, Fjelstul JK. Validation of the rockport fitness walking test in college males and females. Res $Q$ Exerc Sport. 1994;65(2):152-158.

29. Holick MF. The vitamin D epidemic and its health consequences. J Nutr. 2005;135(11):2739S-2748S.

30. Gilsanz V, Kremer A, Mo AO, Wren TA, Kremer R. Vitamin D status and its relation to muscle mass and muscle fat in young women. $J$ Clin Endocrinol Metab. 2010;95(4):1595-1601.

31. Girgis CM, Clifton-Bligh RJ, Hamrick MW, Holick MF, Gunton JE. The roles of vitamin D in skeletal muscle: form, function, and metabolism. Endocr Rev. 2013;34(1):33-83.

32. Endo I, Inoue D, Mitsui T, et al. Deletion of vitamin D receptor gene in mice results in abnormal skeletal muscle development with deregulated expression of myoregulatory transcription factors. Endocrinology. 2003;144(12):5138-5144

33. Granic A, Hill T, Davies K, et al. Vitamin D status, muscle strength and physical performance decline in very old adults: a prospective study. Nutrients. 2017;9(4):379.

34. Allali F, El Aichaoui S, Khazani H, et al. High prevalence of hypovitaminosis D in Morocco: relationship to lifestyle, physical performance, bone markers, and bone mineral density. Semin Arthritis Rheum. 2009; 38(6):444-451. 
35. Garnero P, Munoz F, Sornay-Rendu E, Delmas PD. Associations of vitamin $\mathrm{D}$ status with bone mineral density, bone turnover, bone loss and fracture risk in healthy postmenopausal women. The OFELY study. Bone. 2007;40(3):716-722.

36. Glerup H, Mikkelsen K, Poulsen L, et al. Hypovitaminosis D myopathy without biochemical signs of osteomalacic bone involvement. Calcif Tissue Int. 2000;66(6):419-424.

37. Dimchev GA, Al-Shanti N, Stewart CE. Phospho-tyrosine phosphatase inhibitor $\mathrm{Bpv}$ (Hopic) enhances $\mathrm{C} 2 \mathrm{C} 12$ myoblast migration in vitro. Requirement of PI3K/AKT and MAPK/ERK pathways. J Muscle Res Cell Motil. 2013;34(2):125-136.

38. Książek A, Kawczyński A, Słowińska-Lisowska M. Relationship between 25(OH)D levels and skeletal muscle stiffness in athletes Preliminary study. Sci Sports. 2017;32(4):229-234.

39. Hamilton B. Vitamin D and human skeletal muscle. Scand J Med Sci Sports. 2010;20(2):182-190.

40. Berg U, Gustafsson T, Sundberg CJ, Kaijser L, Carlsson-Skwirut C, Bang P. Interstitial IGF-I in exercising skeletal muscle in women. Eur J Endocrinol. 2007;157(4):427-435.
41. Ardestani A, Parker B, Mathur S, et al. Relation of vitamin D level to maximal oxygen uptake in adults. Am J Cardiol. 2011;107(8):1246-1249.

42. Gouni-Berthold I, Krone W, Berthold HK. Vitamin D and cardiovascular disease. Curr Vasc Pharmacol. 2009;7(3):414-422.

43. Whaley MH, Kampert JB, Kohl HW, Blair SN. Physical fitness and clustering of risk factors associated with the metabolic syndrome. Med Sci Sports Exerc. 1999;31(2):287-293.

44. Rock CL, Emond JA, Flatt SW, et al. Weight loss is associated with increased serum 25-hydroxyvitamin D in overweight or obese women. Obesity. 2012;20(11):2296-2301.

45. Cassity EP, Redzic M, Teager CR, Thomas DT. The effect of body composition and BMI on 25(OH)D response in vitamin D-supplemented athletes. Eur J Sport Sci. 2016;16(7):773-779.

46. Wortsman J, Matsuoka LY, Chen TC, Lu Z, Holick MF. Decreased bioavailability of vitamin D in obesity. Am J Clin Nutr. 2000;72(3): 690-693.
International Journal of Women's Health

\section{Publish your work in this journal}

The International Journal of Women's Health is an international, peerreviewed open-access journal publishing original research, reports, editorials, reviews and commentaries on all aspects of women's healthcare including gynecology, obstetrics, and breast cancer. The manuscript management system is completely online and includes

\section{Dovepress}

a very quick and fair peer-review system, which is all easy to use. Visit http://www.dovepress.com/testimonials.php to read real quotes from published authors. 